\title{
Quantitative anatomical analysis and clinical experience with mini-pterional and mini-orbitozygomatic approaches for intracranial aneurysm surgery
}

\author{
Kaan Yagmurlu, MD, ${ }^{1}$ Sam Safavi-Abbasi, MD, ${ }^{1}$ Evgenii Belykh, MD, ${ }^{1}$ M. Yashar S. Kalani, MD, PhD, ${ }^{1}$ \\ Peter Nakaji, MD, ${ }^{1}$ Albert L. Rhoton Jr., MD, ${ }^{2}$ Robert F. Spetzler, MD, ${ }^{1}$ and Mark C. Preul, MD ${ }^{1}$ \\ 'Department of Neurosurgery, Barrow Neurological Institute, St. Joseph's Hospital and Medical Center, Phoenix, Arizona; and \\ 2Department of Neurological Surgery, University of Florida, Gainesville, Florida
}

\begin{abstract}
OBJECTIVE The aim of this investigation was to modify the mini-pterional and mini-orbitozygomatic (mini-OZ) approaches in order to reduce the amount of tissue traumatization caused and to compare the use of the 2 approaches in the removal of circle of Willis aneurysms based on the authors' clinical experience and quantitative analysis.
\end{abstract}

METHODS Three formalin-fixed adult cadaveric heads injected with colored silicone were examined. Surgical freedom and angle of attack of the mini-pterional and mini-OZ approaches were measured at 9 anatomical points, and the measurements were compared. The authors also retrospectively reviewed the cases of 396 patients with ruptured and unruptured single aneurysms in the circle of Willis treated by microsurgical techniques at their institution between January 2006 and November 2014.

RESULTS A significant difference in surgical freedom was found in favor of the mini-pterional approach for access to the ipsilateral internal carotid artery (ICA) and middle cerebral artery (MCA) bifurcations, the most distal point of the ipsilateral posterior cerebral artery (PCA), and the basilar artery (BA) tip. No statistically significant differences were found between the mini-pterional and mini-OZ approaches for access to the posterior clinoid process, the most distal point of the superior cerebellar artery (SCA), the anterior communicating artery (ACOA), the contralateral ICA bifurcation, and the most distal point of the contralateral MCA. A trend toward increasing surgical freedom was found for the mini-OZ approach to the ACOA and the contralateral ICA bifurcation. The lengths exposed through the mini-OZ approach were longer than those exposed by the mini-pterional approach for the ipsilateral PCA segment $(11.5 \pm 1.9 \mathrm{~mm})$ between the $B A$ and the most distal point of the $P_{2}$ segment of the PCA, for the ipsilateral SCA $(10.5 \pm 1.1 \mathrm{~mm})$ between the $B A$ and the most distal point of the SCA, and for the contralateral anterior cerebral artery (ACA) $(21 \pm 6.1 \mathrm{~mm})$ between the ICA bifurcation and the most distal point of the $\mathrm{A}_{2}$ segment of the ACA. The exposed length of the contralateral MCA $(24.2 \pm$ $8.6 \mathrm{~mm}$ ) between the contralateral ICA bifurcation and the most distal point of the MCA segment was longer through the mini-pterional approach. The vertical angle of attack (anteroposterior direction) was significantly greater with the minipterional approach than with the mini-OZ approach, except in the ACoA and contralateral ICA bifurcation. The horizontal angle of attack (mediolateral direction) was similar with both approaches, except in the ACoA, contralateral ICA bifurcation, and contralateral MCA bifurcation, where the angle was significantly increased in the mini-OZ approach.

CONCLUSIONS The mini-pterional and mini-OZ approaches, as currently performed in select patients, provide less tissue traumatization (i.e., less temporal muscle manipulation, less brain parenchyma retraction) from the skin to the aneurysm than standard approaches. Anatomical quantitative analysis showed that the mini-OZ approach provides better exposure to the contralateral side for controlling the contralateral parent arteries and multiple aneurysms. The mini-pterional approach has greater surgical freedom (maneuverability) for ipsilateral circle of Willis aneurysms.

https://thejns.org/doi/abs/10.3171/2016.6.JNS16306

KEY WORDS intracranial aneurysm; mini-orbitozygomatic; mini-pterional approach; surgical approaches; anatomy; surgical technique

ABBREVIATIONS $A C A=$ anterior cerebral artery; $\mathrm{ACOA}=$ anterior communicating artery; $\mathrm{BA}=$ basilar artery; ICA = internal carotid artery; $\mathrm{MCA}=$ middle cerebral artery; mini-OZ = mini-orbitozygomatic; $\mathrm{PCA}=$ posterior cerebral artery; $\mathrm{PCOA}=$ posterior communicating artery; $\mathrm{SCA}=$ superior cerebellar artery.

SUBMITTED February 5, 2016. ACCEPTED June 21, 2016.

INCLUDE WHEN CITING Published online November 18, 2016; DOI: 10.3171/2016.6.JNS16306. 
A DVANCES in surgical technology and wider experience in microsurgical techniques have driven modifications in surgical procedure toward minimizing craniotomies. Thus, the mini-pterional and miniorbitozygomatic (mini-OZ) approaches were developed and have become the standard cranial exposures for many neurosurgeons performing neurovascular and neuro-oncological surgery. Clinical and quantitative anatomical analyses have resulted in studies to evaluate and compare the mini-pterional and mini-OZ approaches with other traditional approaches. ${ }^{5,6}$ The classic pterional craniotomy begins with a curvilinear skin incision behind the hairline, proceeds with interfascial or subfascial temporal fascia dissection (or with temporal fascia and muscle reflected as a single layer), and progresses to a frontotemporosphenoidal craniotomy. The modified supraorbital orbitozygomatic approach is similar to the pterional craniotomy but includes the addition of resection of the lateral and superior orbital walls. ${ }^{13}$ The mini-pterional craniotomy is a frontotemporal craniotomy centered on the sphenoid groove that sits at the greater wing of the sphenoid bone, whereas in the mini-OZ craniotomy, the superior orbital rim is removed, as are a small part of the orbital roof, the zygomatic process of the frontal bone, and the frontal bone. ${ }^{5,6}$

Herein, we report the results of our quantitative anatomical analysis of the 2 approaches. We compared the use of the mini-pterional and mini-OZ approaches for removing circle of Willis aneurysms based on our clinical experience in order to elaborate upon and correlate the anatomical results. We also examined previous surgical solutions to determine how to modify the mini-pterional and mini-OZ approaches to reduce tissue traumatization.

\section{Methods}

\section{Anatomical Study}

Five sides of 3 formalin-fixed, adult cadaveric heads injected with colored silicone were examined. The heads were positioned using Mayfield head holders so as to replicate the actual surgical setting. Procedures were performed using the usual microneurosurgical instruments, an operative microscope (Carl Zeiss AG), and an appropriate high-speed drill (Anspach).

\section{Surgical Freedom}

The surgical freedom of the mini-pterional and mini$\mathrm{OZ}$ approaches was measured at 9 anatomical points, and these measurements were compared between the 2 approaches. The 9 points were 1) the tip of the basilar artery (BA); 2) the posterior clinoid process; 3 ) the anterior communicating artery (ACoA); 4) the most distal point of the ipsilateral posterior cerebral artery (PCA); 5) the bifurcation of the ipsilateral internal carotid artery (ICA); 6) the bifurcation of the ipsilateral middle cerebral artery (MCA); 7) the most distal point of the ipsilateral superior cerebellar artery (SCA); 8) the bifurcation of the contralateral MCA; and 9) the bifurcation of the contralateral ICA (Figs. 1-8). Surgical freedom was defined as the maneuverability of instruments within the surgical approach to a selected point in the brain, such as the bifurcation of the ICA.

\section{Angle of Surgical Attack}

The angle of attack concerns the maximum allowable angle of approach in the vertical (anteroposterior) and horizontal (mediolateral) planes. The angles of attack for the mini-pterional and mini-OZ approaches were measured separately for the 9 points mentioned above and were then compared between the 2 approaches (Fig. 9).

\section{Statistical Analysis}

The Holm-Šidák and Dunn methods were used to determine significant differences in exposure areas and angles of attack. A p value of less than 0.05 was considered significant.

\section{Image Guidance System Analysis}

Three adult cadaveric heads were imaged using 3-T MRI, and the MR images were registered on a Stealth Image Guidance workstation (Medtronic Surgical Navigation Technologies) with an accuracy of about $2.0 \mathrm{~mm}$. A probe was used under the microscope to demonstrate the limits of the surgical approaches by touching the probe to the designated 9 points being studied.

\section{Clinical Data}

We retrospectively reviewed the cases of 396 patients with ruptured and unruptured single aneurysms in the circle of Willis who were treated by microsurgical technique at our institution between January 2006 and November 2014 (Table 1). We excluded patients with multiple aneurysms treated in the same operative session. Of the 396 aneurysms, 176 were located at the MCA bifurcation, 77 at the ICA bifurcation, 65 on the ACoA, 58 on the posterior communicating artery (PCoA), 8 at the BA tip, 7 on the PCA, and 5 on the SCA (Fig. 10). The rates of use for the mini-pterional and mini-OZ approaches were compared for these cases.

\section{Results \\ Head Positioning}

The correct head position is critical to provide the surgeon with a comfortable visual angle, to minimize brain retraction, and to accommodate the surgical plan. Tilting the head laterally, especially in surgery for ACoA aneurysms, allows a surgical route that will provide access to the contralateral $\mathrm{A}_{1}$ segment of the anterior cerebral artery (ACA), the contralateral $\mathrm{A}_{2}$ segment of the ACA, and the contralateral ICA. For a mini-OZ approach, the head position for ACoA aneurysms includes rotation $20^{\circ}$ to $30^{\circ}$ contralaterally and moderate lateral tilt. If the aneurysm projects downward and forward or downward and backward, head extension (retroflexion) of $10^{\circ}$ minimizes the need for frontal lobe retraction, resulting in enough space between the orbital roof and frontal lobe. The head is extended so that the malar eminence is at the uppermost point. For an upward-forward-projecting aneurysm, the head is rotated $15^{\circ}$ to $20^{\circ}$ contralaterally, with moderate lateral tilt, and optimal exposure of the aneurysm is achieved with minimal extension and removal of the gyrus rectus. For an upward-backward-projecting aneurysm, the head is rotated only $10^{\circ}$ to $15^{\circ}$ to the contralateral side to provide a shorter 

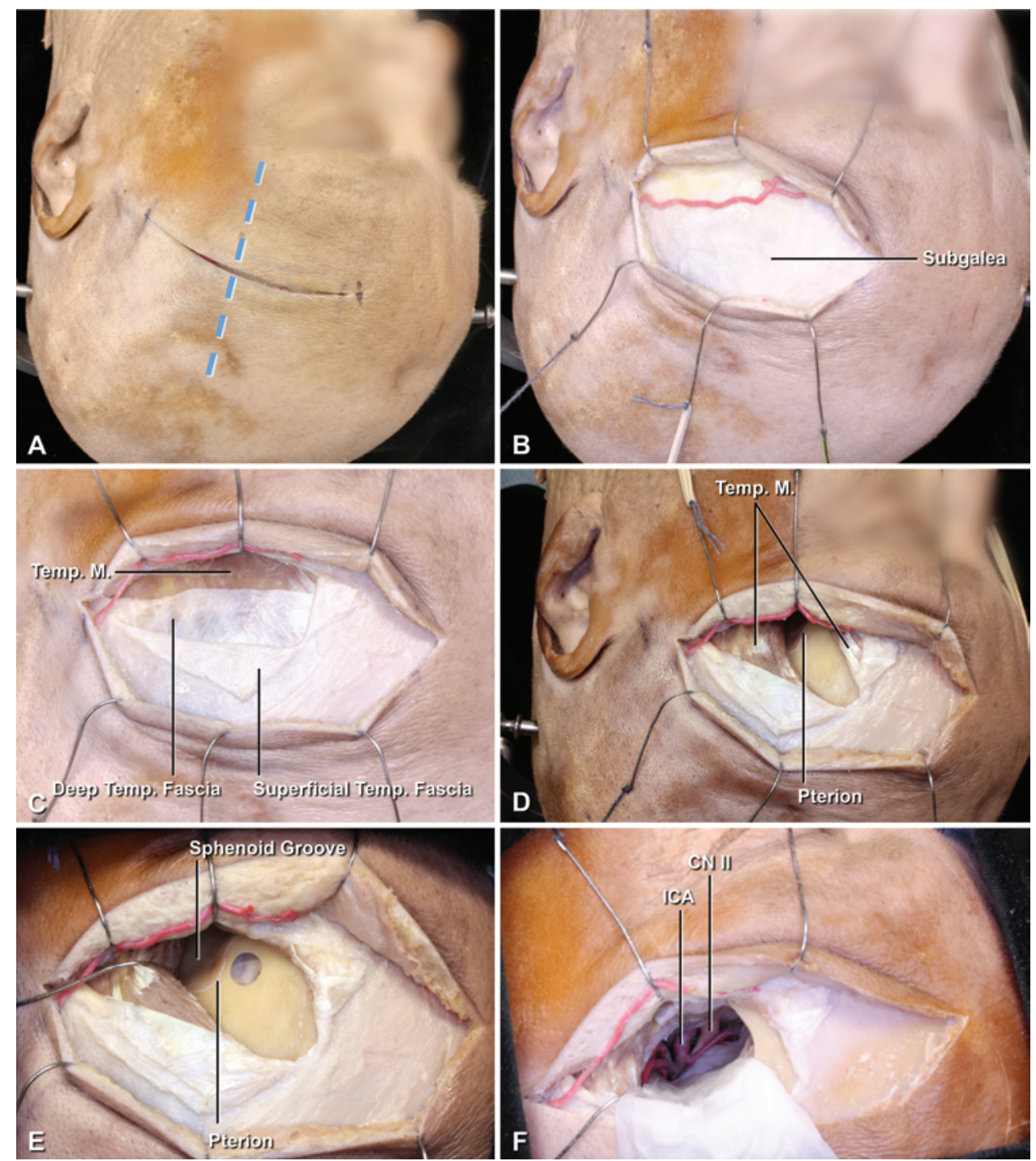

FIG. 1. The steps of the mini-pterional approach. A: A curvilinear incision is centered on the extension line of the sphenoid groove (blue dashed line) $1 \mathrm{~cm}$ behind the hairline. B: The subcutaneous tissue, frontal branch of the superficial temporal artery, and superficial fat pad are exposed after the galeal flap is reflected toward the temporal fossa. C: In the subfascial dissection, the superficial temporal fascia and the deep temporal fascia are cut to expose the temporalis muscle fiber bundles. D: The temporalis muscle is split in the same direction as its fiber bundles to expose the pterion and the sphenoid groove. E: A bur hole is placed just anterior to the pterion in the frontal bone. F: After the craniotomy, the dura is opened and the sylvian fissure is dissected, exposing the opticocarotid complex. $\mathrm{CN}=$ cranial nerve; $\mathrm{ICA}=$ internal carotid artery; Temp. = temporal; Temp. $\mathrm{M}$. = temporalis muscle. Facial features have been blurred to protect the identity of the donor. Used with permission from Barrow Neurological Institute, Phoenix, Arizona. Figure is available in color online only.

distance to the interhemispheric fissure from the craniotomy site. For access to higher-level ACoA aneurysms, the interhemispheric approach may be preferable.

For the mini-OZ approach for ICA bifurcation aneurysms, the head is rotated $15^{\circ}$ to the contralateral side. Additionally, an upward-projecting aneurysm is often better visualized with a $10^{\circ}$ head extension (retroflexion), whereas a downward-projecting aneurysm is better visualized with a neutral position.

For the mini-pterional approach for MCA bifurcation aneurysms, the head is rotated $30^{\circ}$ to the contralateral side, with head extension. Extreme rotation may cause the surgical view to be obstructed by the temporal lobe.

\section{Surgical Technique}

The Mini-Pterional Approach

For the mini-pterional approach (Figs. 1-3), the patient is placed in the supine position with the table tilted $10^{\circ}$ to $15^{\circ}$ so that the head is elevated above the level of the heart. The patient's head is positioned vertex down to allow gravitational retraction of the frontal and temporal lobes from the skull base and is rigidly fixed with a Mayfield head holder. The head is rotated toward the contralateral side according to the anatomical demands of the pathology.

The sphenoid groove of the greater wing of the sphe- 


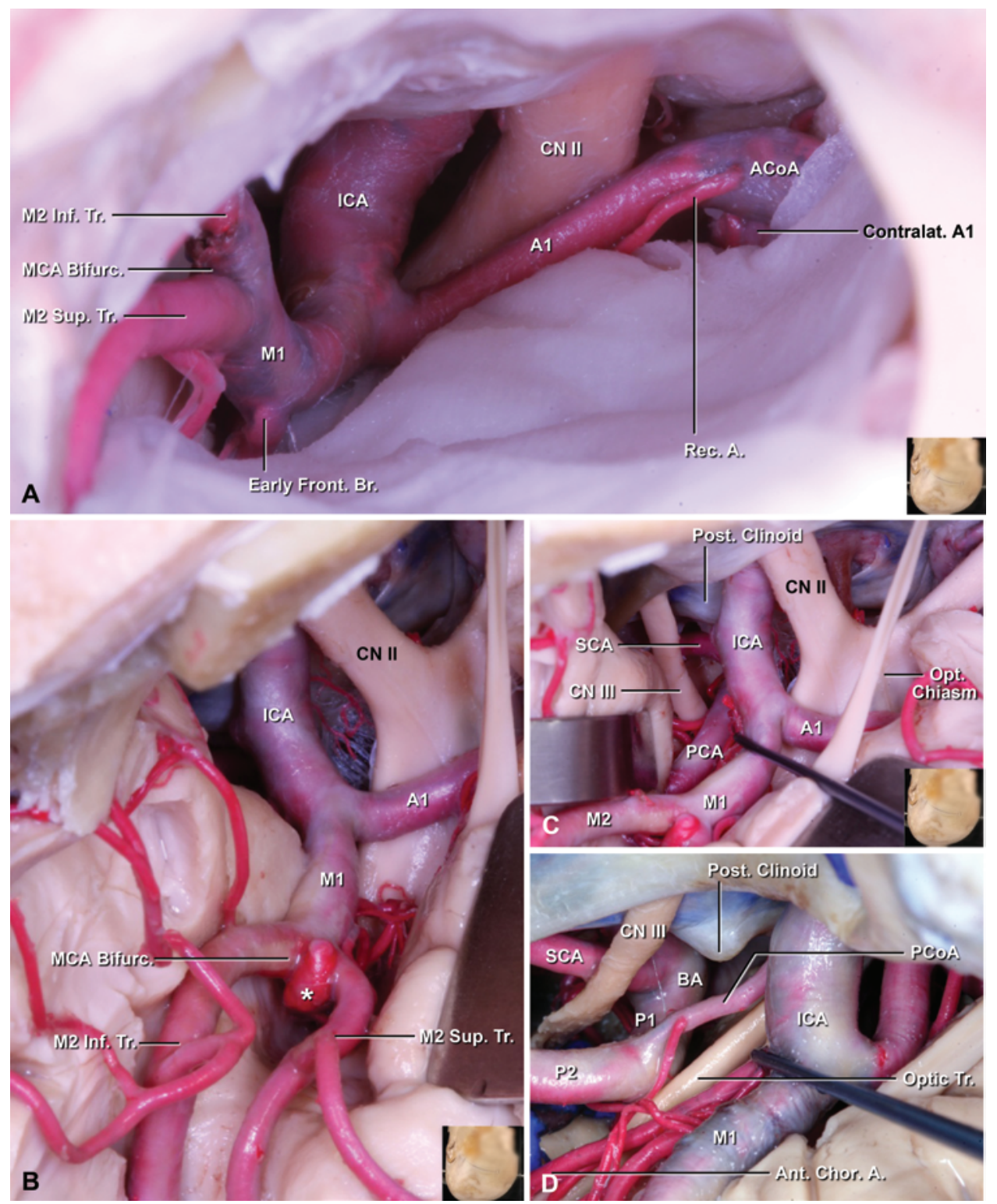

FIG. 2. A: Enlarged view of the opticocarotid complex, showing the exposure of the ICA, the ACA ( $A_{1}$ segment and $\left.A C O A\right)$, the MCA ( $M_{1}$ and $M_{2}$ segments), and the optic nerve. B: In a different specimen, the proximal sylvian fissure has been opened to expose the $A_{1}$ segment of the ACA, the $M_{1}$ and $M_{2}$ segments of the MCA, and the ICA. The asterisk denotes an incidental aneurysm. $C$ and $D$ : Exposure of the $A_{1}, M_{1}, M_{2}, P_{1}$, and $P_{2}$ segments of the PCA, the ICA, the PCoA, the anterior choroidal artery, the SCA, and CN III. A1 = A, segment of the ACA; Ant. Chor. A. = anterior choroidal artery; $B A=$ basilar artery; Bifurc. = bifurcation; Contralat. = contralateral; Inf. Tr. = inferior trunk; Front. $B r .=$ frontal branch; $M 1=M_{1}$ segment of the $M C A ; M 2=M_{2}$ segment of the MCA; Opt. = optic; $P 1=P_{1}$ segment of the PCA; $P 2=P_{2}$ segment of the PCA; Post. = posterior; Rec. $A .=$ recurrent artery; SCA = superior cerebellar artery; Sup. Tr. = superior trunk; Tr. = tract. The dissections in Panels B-D were prepared by Kaan Yagmurlu, MD, while he was working in the lab of Dr. Rhoton at the University of Florida, and the images for B-D are reproduced with permission from the Rhoton Collection. (http://rhoton.ineurodb.org), CC BY-NC-SA 4.0 (http://creativecommons.org/licenses/ by-nc-sa/4.0). Panel A used with permission from Barrow Neurological Institute, Phoenix, Arizona. Facial features have been blurred to protect the identity of the donor. Figure is available in color online only.

noid bone is identified by palpating behind the lateral rim of the orbit. The axis of the sphenoid groove of the greater wing of the sphenoid bone is centered in relation to the curvilinear skin incision, which is made $1 \mathrm{~cm}$ behind the hairline (Fig. 1). The galea is incised and the galeal flap is reflected toward the temporal floor to expose the superficial temporal fascia. At the medial to the superior tempo- ral line, the temporal (frontal) branch of the facial nerve lies in the interfascial fat pad. ${ }^{17}$

The subfascial dissection for the mini-pterional approach is performed about $4 \mathrm{~cm}$ above the lateral orbital rim. The superficial and deep temporal fascial layers are dissected until the temporalis muscle is identified. The fiber bundle of the temporalis muscle is split over the sphe- 

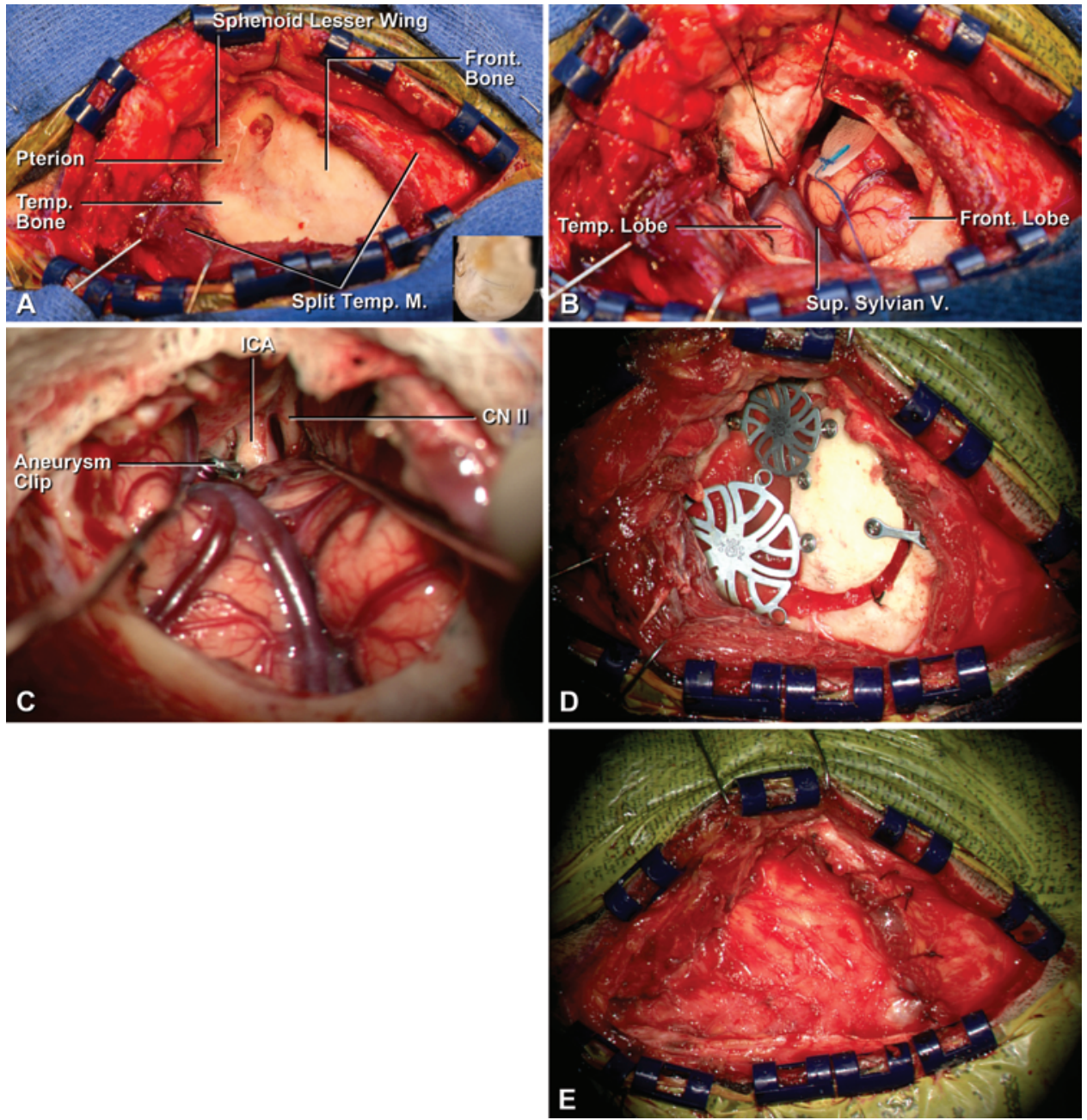

FIG. 3. Intraoperative photographs after the galeal flap was reflected and the subfascial dissection was made. A: The temporalis muscle was split to expose the frontal, sphenoid, and temporal bones, and a bur hole was placed anterior to the pterion in the frontal bone. B: After the craniotomy and removal of the sphenoid ridge, the dura was opened in a curvilinear fashion and tacked up toward the temporal fossa. C: The proximal sylvian fissure was dissected and the Liliequist membrane was opened, releasing the cerebrospinal fluid and allowing clipping of the PCoA aneurysm. D: The craniotomy flap was replaced using titanium miniplates. E: Reconstruction of the temporalis muscle. Front. = frontal; Sup. = superior; V. = vein. Facial features have been blurred to protect the identity of the donor. Used with permission from Barrow Neurological Institute, Phoenix, Arizona. Figure is available in color online only.

noid groove and pterion, then retracted laterally using fish hooks to expose the greater wing of the sphenoid bone (sphenoid groove), $1 \mathrm{~cm}$ of the frontal bone, and $1 \mathrm{~cm}$ of the temporal bone laterally to the sphenoid groove. A bur hole is placed just anterior to the pterion in the frontal bone. The first bone cut is made from the frontal bone to the edge of the greater wing of the sphenoid bone (sphenoid groove), then the temporal bone is cut starting at the bur hole. After the frontal and temporal bones are cut, the sphenoid groove that indicates the outer layer of the sphenoid ridge is cut with a chisel, creating a $3 \times 3-\mathrm{cm}$ craniotomy centered on the greater wing of the sphenoid bone (sphenoid groove) (Fig. 1).

The dura mater is separated from the craniotomy flap using a dissector. The inner layer of the lesser wing of the sphenoid bone (the sphenoid ridge) is usually composed of cortical bone that is easily removed. After the crani- otomy flap is removed, the middle meningeal artery is coagulated, and the proximal part of the sphenoid ridge is removed using a high-speed drill and rongeur until the orbitomeningeal fold is reached. If necessary, an anterior clinoidectomy may be performed. The dura is opened in a semilunar fashion, reflected, and tacked toward the temporal fossa.

In the intradural stage, the anterior clinoid process is followed until the optic and carotid cisterns are reached, then the membrane of Liliequist between the ICA and the optic nerve is opened, releasing cerebrospinal fluid and allowing for brain relaxation (Fig. 3). If the brain is tight, the lamina terminalis can also be opened. The $\mathrm{A}_{1}$ segment and the ACoA can then be exposed with less brain tissue retraction. The proximal sylvian fissure dissection requires exposure of the MCA segments, PCoA, PCA, and $\mathrm{BA}$. The superficial veins of the sylvian fissure are pre- 

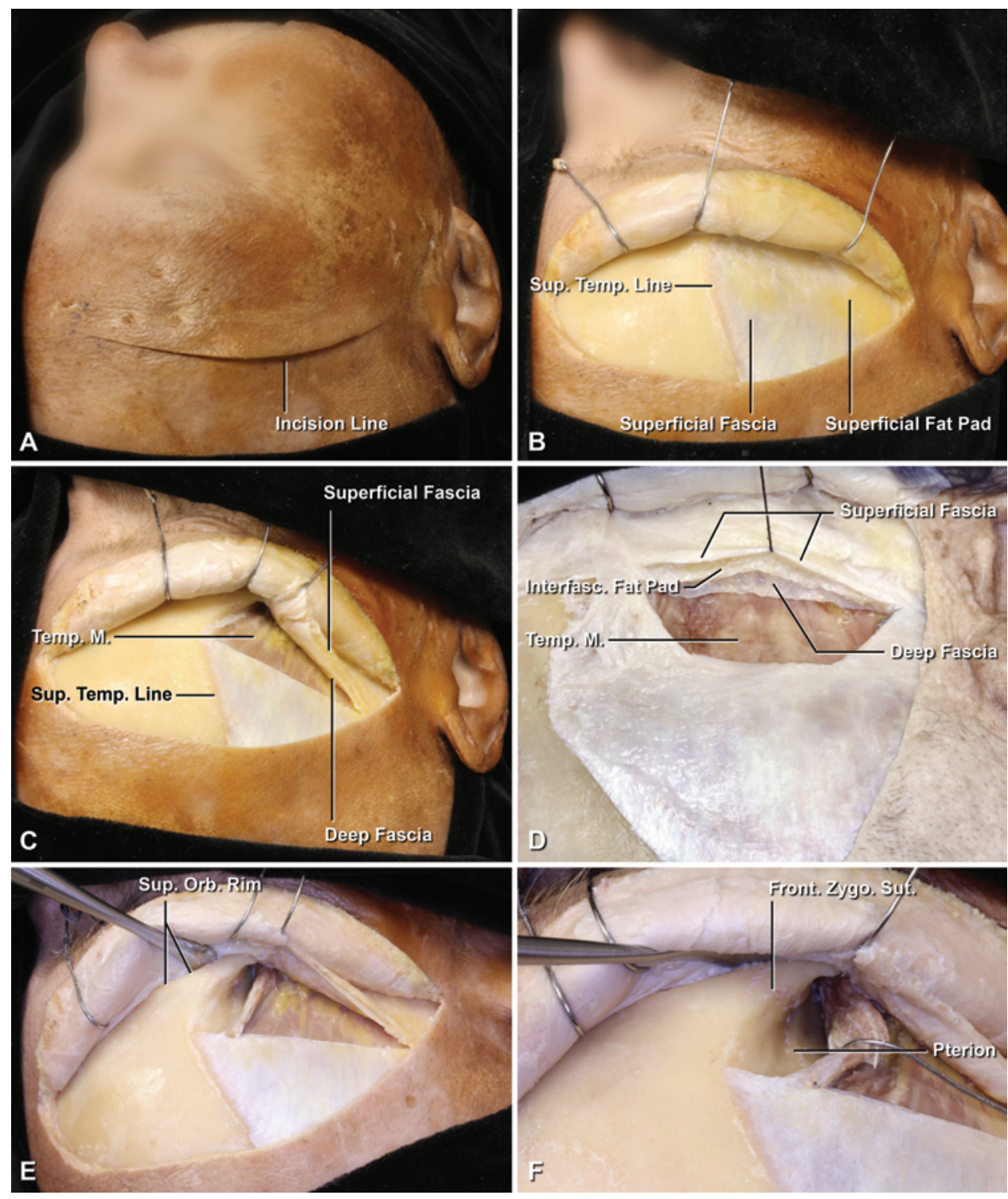

FIG. 4. The steps of the mini-OZ approach. A: The curvilinear incision line extends from $1 \mathrm{~cm}$ anterosuperior to the tragus and ends at the same sagittal level as the midpupillary line. B: After the skin incision, the galeal flap is reflected toward the temporal fossa. The superficial fascia and the superficial fat pad are also exposed. C: Subfascial dissection is performed to preserve the temporal (frontal) branches of the facial nerve. D: In a different specimen, the interfascial fat pad is shown located between the superficial fascia and the deep temporal fascia. The facial nerve travels through the interfascial fat pad. E and F: The anterosuperior edge of the temporalis muscle and fascia are mobilized subperiosteally from the superior temporal line and retracted toward the temporal fossa to expose the lateral orbital rim, the frontozygomatic suture, which is the junction of the zygomatic process of the frontal bone and frontal process of the zygomatic bone, and a part of the frontal process of the zygomatic bone. Front. Zygo. Sut. = frontozygomatic suture; Interfasc. $=$ interfascial; Sup. Orb. Rim = superior orbital rim; Sup. Temp. Line = superior temporal line. Facial features have been blurred to protect the identity of the donor. Used with permission from Barrow Neurological Institute, Phoenix, Arizona. Figure is available in color online only.

served and usually are left attached to the temporal lobe at the beginning of the sylvian fissure dissection.

\section{The Mini-Orbitozygomatic Approach}

For the mini-OZ approach (Figs. 4-7), the patient is placed in the supine position with the head elevated $10^{\circ}$ to $15^{\circ}$ above the level of the heart. The head is rotated to the contralateral aspect according to location of the pathology, then extended until the malar eminence is the highest point in the operative field. This maneuver allows gravitational retraction of the frontal and temporal lobes away from the skull base. The head is extended according to aneurysm location, then fixed rigidly into position.

A curvilinear incision is made starting $1 \mathrm{~cm}$ anterior and superior to the tragus at the root of the zygomatic arch and ending at the level of the ipsilateral midpupillary line, behind the hairline (Fig. 4). The galeal flap is reflected toward the temporal fossa. ${ }^{17}$ The subfascial dissection is 

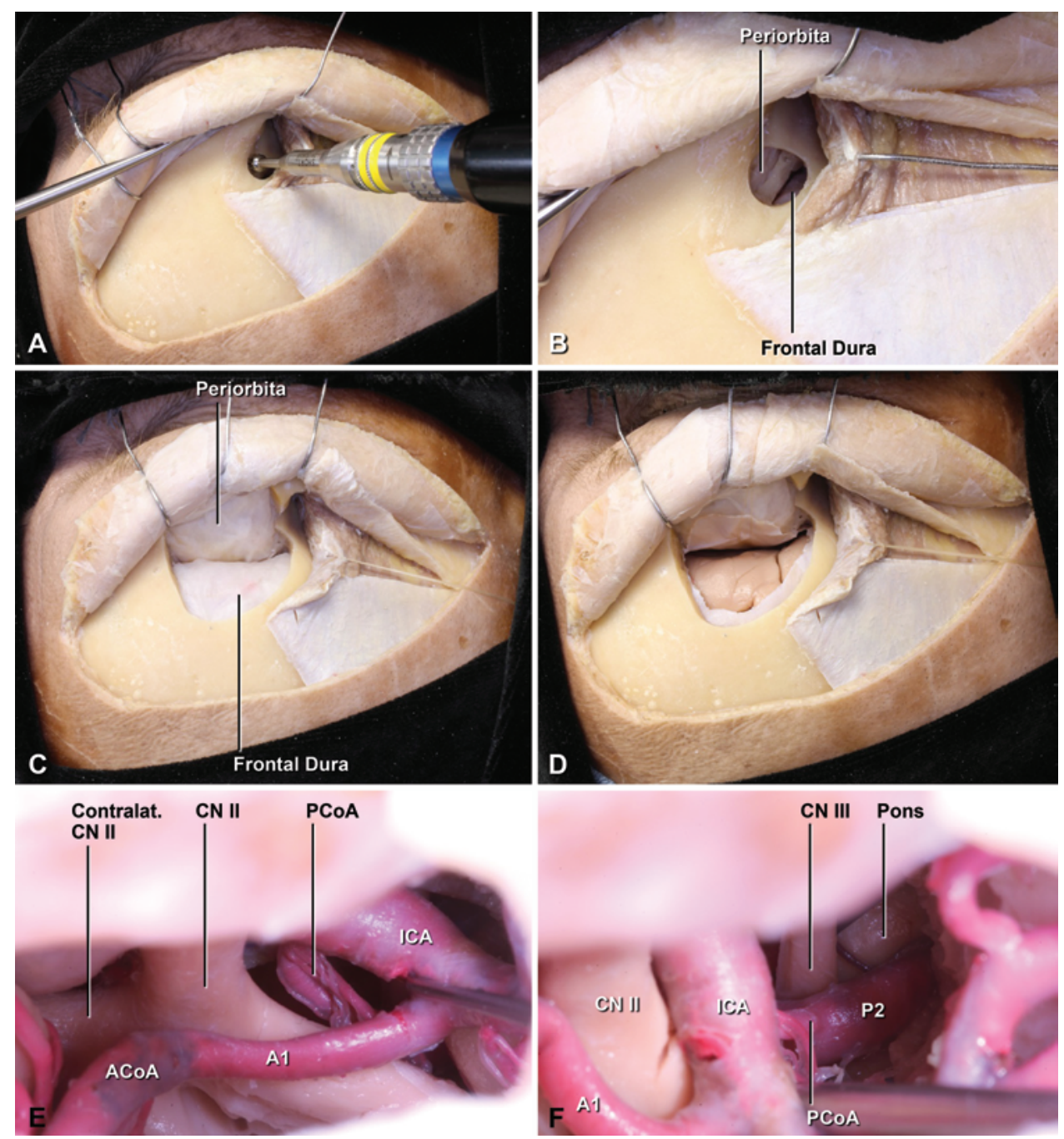

FIG. 5. A: A bur hole is placed at the MacCarty keyhole, located $5 \mathrm{~mm}$ superior and $5 \mathrm{~mm}$ posterior to the frontozygomatic suture, by holding the drill at a $45^{\circ}$ angle to the temporal squamous bone. B: The MacCarty keyhole provides access to both the periorbita and the intracranial area. C: After removal of the craniotomy flap. D: The curvilinear incision and reflection and tacking up of the dura. $\mathbf{E}$ and $\mathrm{F}$ : The subfrontal route is followed to reach the base of the brain; enlarged view of the neurovascular structures and cranial nerves exposed through the mini-OZ approach. Used with permission from Barrow Neurological Institute, Phoenix, Arizona. Figure is available in color online only.

performed approximately $4 \mathrm{~cm}$ above the lateral orbital rim and just above the interfascial fat pad to preserve the branches of the facial nerve when exposing the frontozygomatic suture and $5 \mathrm{~mm}$ of the frontal process of the zygomatic bone. The anterosuperior edge of the temporalis muscle and fascia are mobilized subperiosteally from the superior temporal line and retracted toward the temporal fossa.

A bur hole at the MacCarty keyhole point is placed by holding the drill at a $45^{\circ}$ angle to the surface of the temporal squamous bone (Fig. 5). The periorbita is stripped from the superior and lateral orbital wall, starting at the level of the frontozygomatic suture where it attaches tightly to the suture. A $3 \times 3-\mathrm{cm}$ craniotomy is then performed that includes the frontal bone, the superior orbital rim, the zygomatic process of the frontal bone, and part of the orbital roof. After the superior orbital rim and $5 \mathrm{~mm}$ inferior to the frontozygomatic suture have been cut, a chisel is used to remove the orbital roof. The lateral border of the exposure corresponds to the sphenoid ridge and the frontal edge of the sylvian fissure. If a more lateral exposure is needed, part of the lateral orbital roof and sphenoid ridge may be removed by drilling. The dura is incised in a semilunar fashion, reflected, and tacked toward the orbita (Fig. 7).

\section{Surgical Freedom}

A significant difference was found in favor of the mini-pterional approach for surgical freedom for access to the ipsilateral ICA and MCA bifurcations, the most distal point of the ipsilateral PCA, and the BA tip (Fig. 8). No significant difference was found between the minipterional and mini-OZ approaches for access to the posterior clinoid process, the most distal point of the SCA, the ACoA, the contralateral ICA bifurcation, and the most 

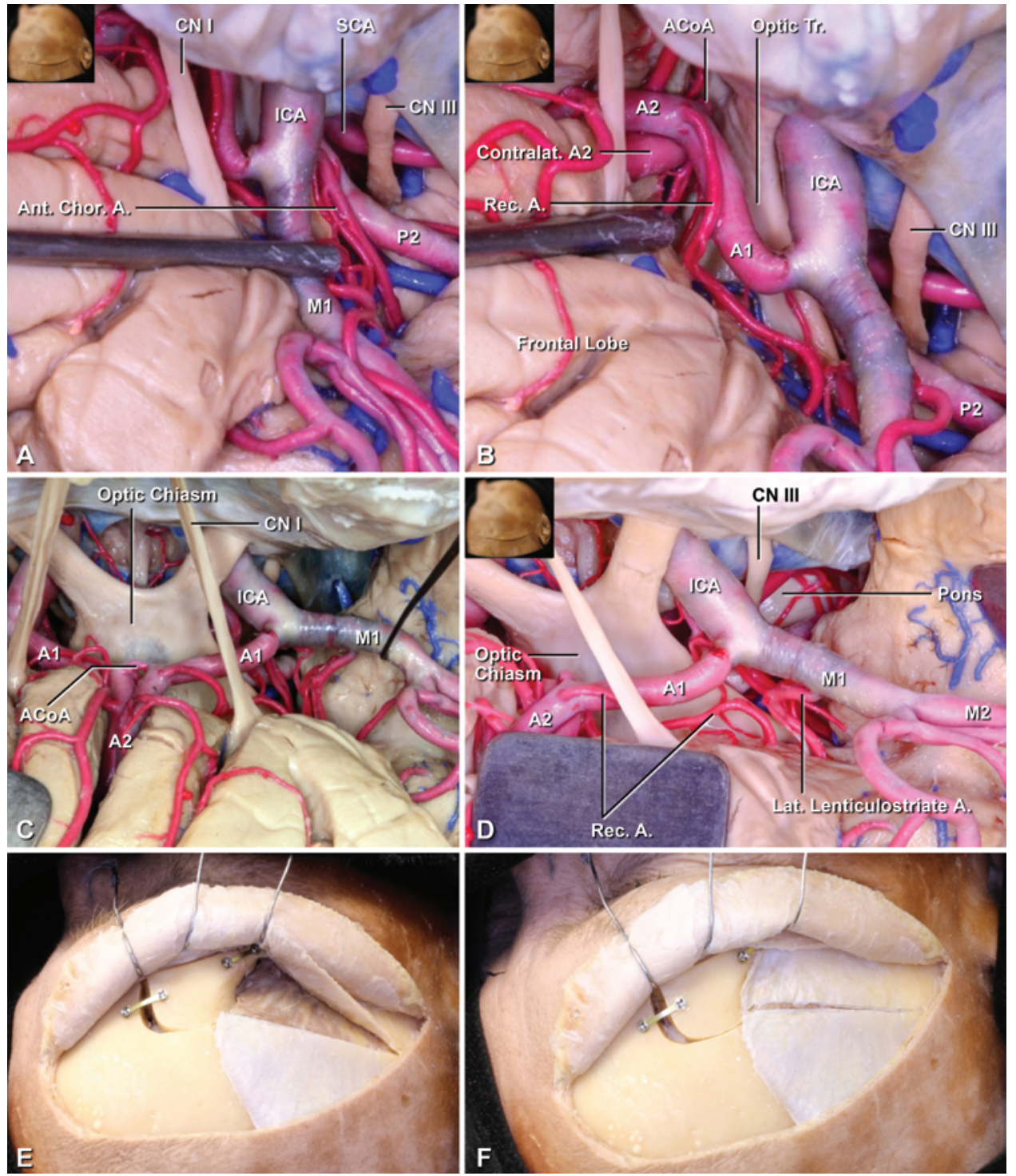

FIG. 6. A-D: In another specimen, the neurovascular structures and cranial nerves at the base of the brain are shown in an enlarged view from different angles. E: After a watertight dural closure, the bone flap is replaced and attached to the free edge of the bones using titanium miniplates and $(\mathbf{F})$ the mobilized edge of the temporal fascia is attached to the superior temporal line. A. = artery; Lat. = lateral; Rec. A. = recurrent artery. The dissections in Panels A-D were prepared by Kaan Yagmurlu, MD, while he was working in the lab of Dr. Rhoton at the University of Florida, and the images in Panels A-D are reproduced with permission from the Rhoton Collection. (http://rhoton.ineurodb.org), CC BY-NC-SA 4.0 (http://creativecommons.org/licenses/by-nc-sa/4.0). Panels $\mathrm{E}$ and $\mathrm{F}$ used with permission from Barrow Neurological Institute, Phoenix, Arizona. Facial features have been blurred to protect the identity of the donor. Figure is available in color online only.

distal point of the contralateral MCA. There was a trend toward increased surgical freedom with the mini-OZ approach to the ACoA and the contralateral ICA bifurcation. Although the difference was not statistically significant, exposure tended to be longer through the mini-OZ approach than through the mini-pterional approach for the length of the ipsilateral PCA segment (mean $11.5 \pm 1.9$ $\mathrm{mm}$ ) between the BA and the most distal point of the $\mathrm{P}_{2}$ segment of the PCA; for the length of the ipsilateral SCA $(10.5 \pm 1.1 \mathrm{~mm})$ between the BA and the most distal point of the SCA; and for the length of the contralateral ACA $(21 \pm 6.1 \mathrm{~mm})$ between the ICA bifurcation and the most distal point of the $\mathrm{A}_{2}$ segment of the ACA (Fig. 11). Exposure also tended to be longer through the mini-pterional approach for the length of the contralateral MCA (24.2 $\pm 8.6 \mathrm{~mm}$ ) between the contralateral ICA bifurcation and the most distal point of the MCA segment (Fig. 11). Because the mini-pterional craniotomy is placed closer to the base of the brain than the mini-OZ craniotomy, it provides more exposure of the contralateral MCA as it ascends into the sylvian fissure.

\section{Angle of Attack}

We determined that the vertical angle of attack (antero- 

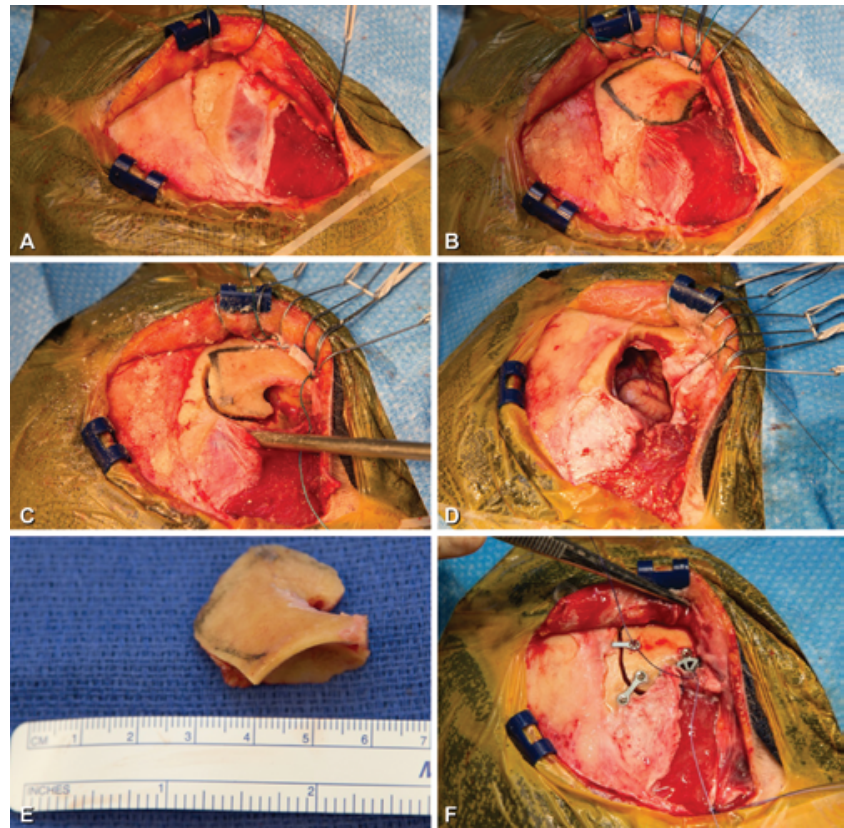

FIG. 7. Intraoperative pictures. A: Reflection of the galeal flap toward the temporal fossa and the subfascial dissection. B: The anterosuperior edge of the temporalis muscle and fascia freed from the superior temporal line, with the craniotomy marked. C: The craniotomy. D: The dura opened in a curvilinear shape and tacked up to expose the frontal lobe. E: The $3 \times 3-\mathrm{cm}$ craniotomy flap composed of the superior orbital rim, zygomatic process of the frontal bone, part of the orbital roof, and part of the frontal bone. F: Replacement of the bone flap using the titanium miniplates and the attachment of the free edge of the temporalis muscle and fascia. Used with permission from Barrow Neurological Institute, Phoenix, Arizona. Figure is available in color online only.

posterior direction) was significantly greater in the minipterional approach than in the mini-OZ approach, except for the ACoA and the contralateral ICA bifurcation. The horizontal angle of attack (mediolateral direction) was similar in both approaches, except for the ACoA, the contralateral ICA bifurcation, and the contralateral MCA bifurcation, where these angles were significantly increased in the mini-OZ approach (Fig. 9).

\section{Clinical Data}

Table 1 and Fig. 10 provide information on the preferred surgical approaches for patients with MCA bifurcation aneurysms, ICA bifurcation aneurysms, ACoA aneurysms, PCoA aneurysms, BA tip aneurysms, PCA aneurysms, and SCA aneurysms. These surgeries were performed by different surgeons at our institution who have varying predilections for the approach. Therefore, we note the rates of the surgical approaches by features of the aneurysms, such as the location, type, and size to illustrate a common opinion at our institution. Notably, the most determinant factor in choosing the surgical approach was the location of the aneurysm.

\section{Discussion}

\section{Minimally Invasive Surgery}

Advances in surgical technology and experienced mi- crosurgical techniques have led to confidence in performing minimally invasive surgical techniques, which provide less traumatic surgical routes than those provided by traditional techniques. In aneurysm surgery, the choice of exposure is paramount, and the principal goals are safe dissection of the aneurysm, preservation of the perforating vessels, and complete exclusion of the aneurysm from the circulation in a manner that neither endangers parent vessels nor leaves an aneurysmal remnant. The goal of the keyhole approach is to minimize tissue traumatization in the surgical route from skin to lesion (e.g., for intra- or extraaxial tumors and aneurysms); the goal is not a small craniotomy. With the keyhole approach, the lesion is reached by using the natural spaces and fissures of the brain. Appropriately placed keyhole craniotomies can provide the same exposure as that provided by traditional craniotomies. ${ }^{1,8}$

Clinical and anatomical studies have shown that the keyhole approach in surgery provides minimum tissue traumatization, fast recovery, and good cosmetic results. ${ }^{4,9}$, ${ }^{12,16}$ For instance, in surgery for anterior circulation aneurysms, removal of the superior orbital rim in a $3 \times 3-\mathrm{cm}$ mini-OZ craniotomy, and the use of the subfrontal route, requires less frontal lobe retraction than the $4 \times 4-\mathrm{cm}$ pterional craniotomy. The mini-pterional approach allows access with dissection of only the proximal sylvian fissure, while providing the same exposure to the base of the brain as the full sylvian fissure dissection in the pterional approach. ${ }^{7}$ Moreover, some studies have shown that augmenting the size of the craniotomy does not result in increased working area at the depth of the lesion; therefore, correct placement of the craniotomy is more important than its size. ${ }^{3,6}$ Finally, the mini-OZ and mini-pterional approaches can be modified according to the features of the lesion to allow a lesion-based surgical strategy instead of using the traditional techniques to perform the same procedures for different lesions.., 13

Notably, we prefer the mini-OZ and mini-pterional approaches in elective cases in which the brain is slack, but not in complicated cases in which the brain is tight or in the presence of subarachnoid hemorrhage. For this reason, in the rest of the cases reported in Table 1, the operations were performed using traditional pterional and orbitozygomatic approaches.

In practical terms, a greater angle of attack or surgical freedom of the surgical approach translates to less brain retraction and manipulation to expose the aneurysm. The mini-OZ and mini-pterional approaches provide less manipulation of the temporal muscle, which avoids postoperative muscle atrophy and therefore likely produces better cosmetic results. This study was focused only on a comparison of the mini-OZ and mini-pterional approaches, and thus we did not attempt to include more traditional approaches in the same region.

\section{Clinical Experience}

The factors in the selection of approach are the location, projection, and size of the aneurysm, and in patients with multiple aneurysms, the features of the other aneurysms. At our institution, the mini-OZ approach has been preferred over the mini-pterional approach for ACoA, ICA 


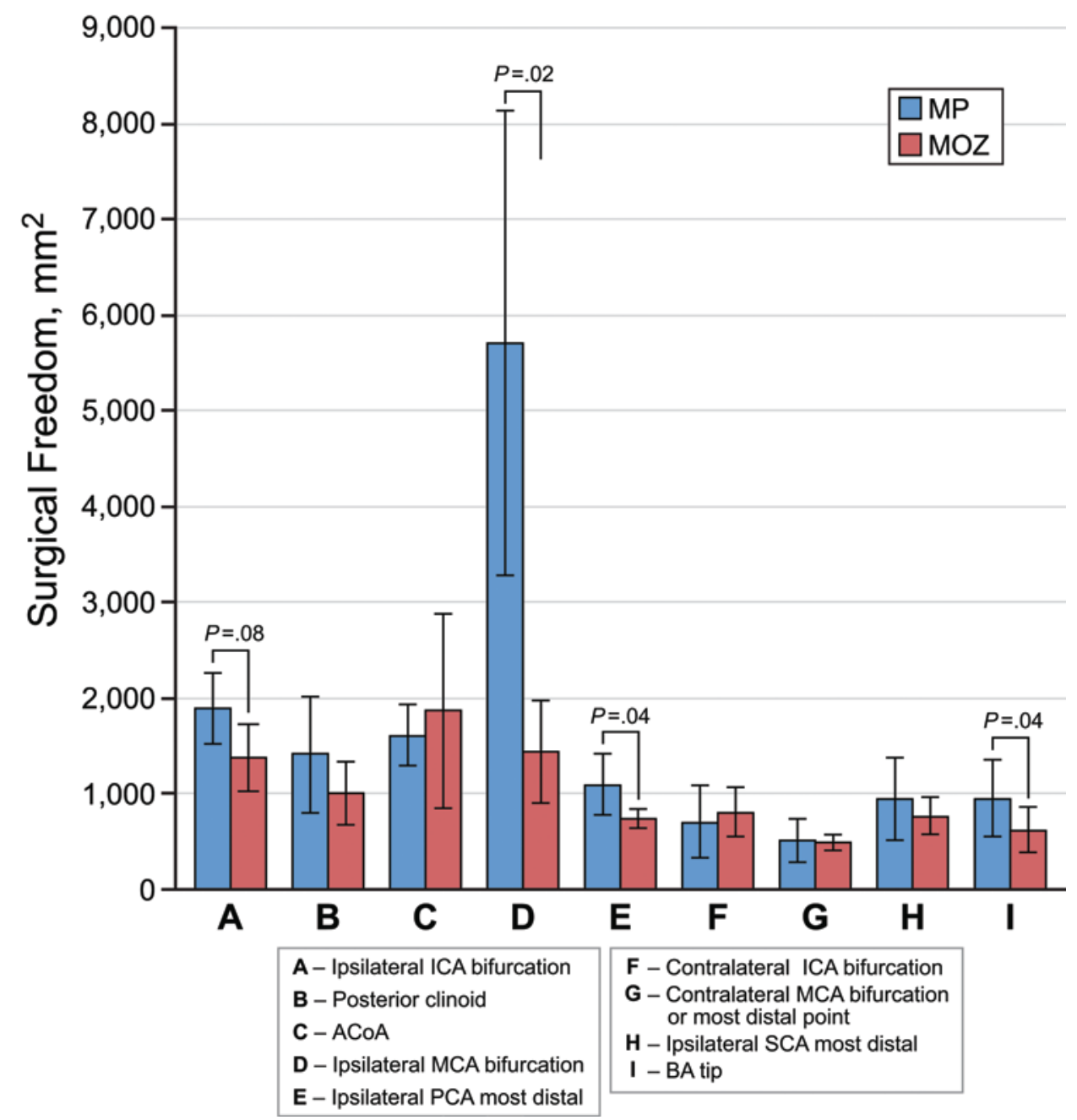

FIG. 8. Surgical freedom by location for the mini-pterional and mini- $\mathrm{OZ}$ approaches. $\mathrm{MOZ}=$ mini-OZ; $\mathrm{MP}=$ mini-pterional. Figure is available in color online only.

bifurcation, and SCA aneurysms. Our surgical experience and anatomical surgical freedom measurements indicate that the mini-OZ approach provides the greater exposure for ACoA aneurysms located high in the interhemispheric fissure and for upward- or backward-oriented aneurysms (which have a close relationship with perforator arteries) than the exposure provided by the mini-pterional approach, either with or without removal of the gyrus rectus. The mini-OZ approach is also a more appropriate option in patients with an ACoA complex that is vertically twisted to the contralateral side. Additionally, the contralateral $\mathrm{ACoA}$, the $\mathrm{A}_{1}$ and $\mathrm{A}_{2}$ segments of the $\mathrm{ACA}$, and the junction of the ACoA and the $A_{1}$ and $A_{2}$ segments may be better controlled through the mini-OZ approach. With respect to the treatment of ICA bifurcation aneurysms, the usage rates of the mini-OZ and mini-pterional approaches are similar, but the mini-OZ approach has been used more often for larger $(6.42 \pm 3.35 \mathrm{~mm})$ aneurysms in this location. The mini-OZ approach was also preferred over the mini-pterional approach for high-riding ICA aneurysms or those in the frontal and temporal lobes.
For SCA aneurysms, we used the mini-OZ approach among other supratentorial routes such as the subtemporal, Kawase, or mini-pterional approach. Although we found no significant difference between the surgical freedom of the mini-OZ and mini-pterional approaches to the SCA, the uncus of the temporal lobe blocked the mini-pterional transsylvian route to the SCA.

The mini-OZ approach also provided a longer exposure to the length of the SCA than that provided by the minipterional approach. In larger $(8.42 \pm 6.01 \mathrm{~mm})$ PCoA aneurysms, the mini-pterional approach was used more often than the mini-OZ approach. The mini-pterional approach provided a significant difference in surgical freedom and in vertical and horizontal angles of attack, and it was considered the first choice for MCA bifurcation aneurysms.

\section{Surgical Considerations}

In the previous mini-pterional technique, interfascial dissection was used and the temporalis muscle was reflected to the temporal fossa, leaving a myofascial cuff at the superior temporal line for future reconstruction. ${ }^{5} \mathrm{We}$ 


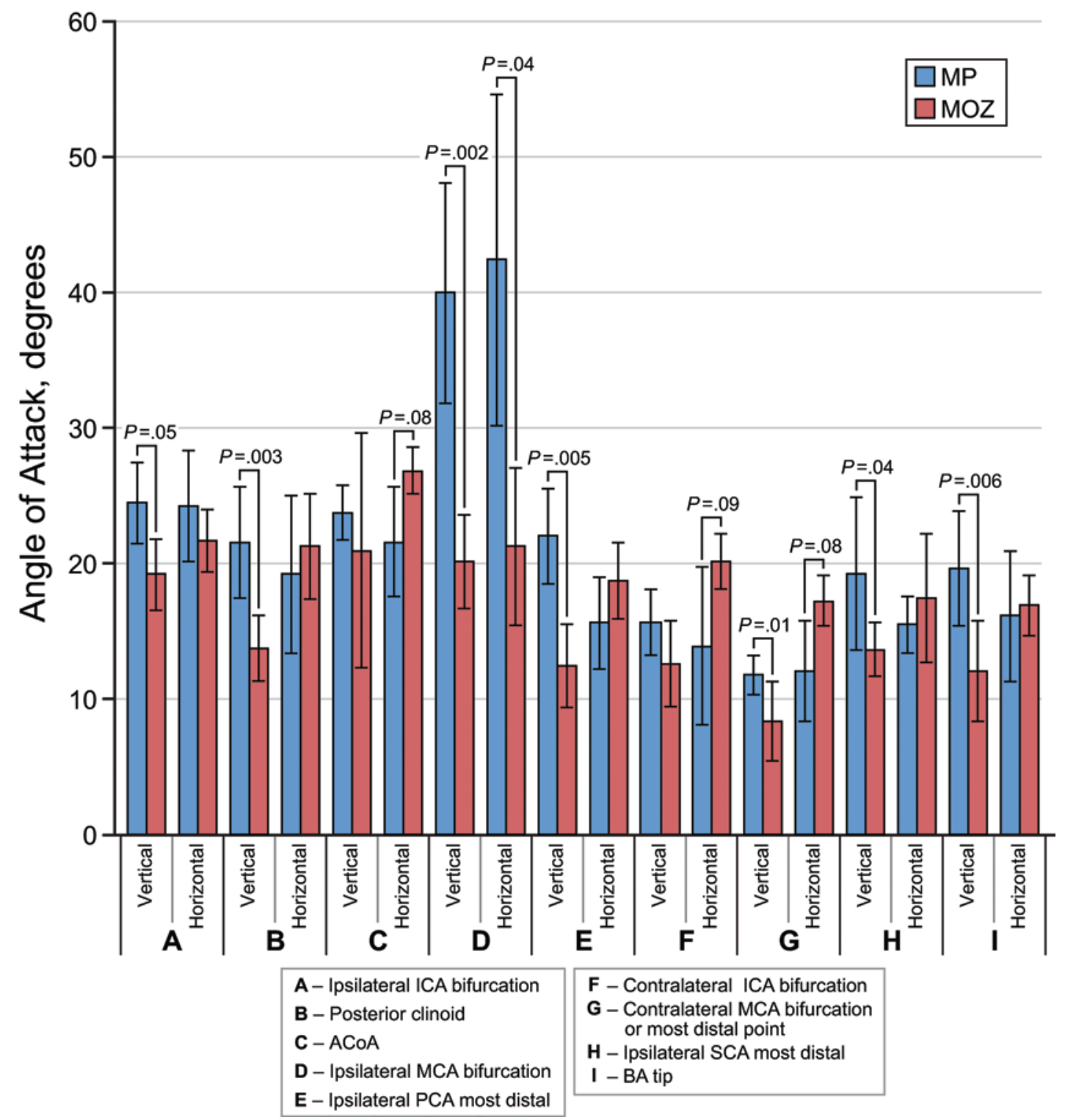

FIG. 9. Vertical and horizontal angle of attack by location for the mini-pterional and mini-OZ approaches. Figure is available in color online only.

have now started splitting and retracting the temporalis muscle subperiosteally, which gives enough bone exposure for the mini-pterional craniotomy, but involves less temporalis muscle traumatization, preventing postoperative muscular atrophy. Subfascial dissection is needed for this muscle-splitting technique. In the current mini-pterional approach, the craniotomy is designed mainly on the basis of aneurysm location and size. The craniotomy flap is made by removing the sphenoid groove, and $1 \mathrm{~cm}$ laterally toward both frontal and temporal sides. Although the superior border of the craniotomy flap is the pterion, the craniotomy flap should be extended up for distal MCA aneurysms.

Some authors have reported aneurysm cases treated with the mini-pterional or pterional keyhole approaches. ${ }^{1,2,5,8,11,14}$ In a comparison of the mini-pterional and pteri- onal approaches, Caplan et al. ${ }^{1}$ concluded that the minipterional approach is a good alternative to the standard pterional craniotomy in anterior circulation aneurysms, but not for aneurysms of the branches of the ICA, the bifurcation of the MCA, and the ICA. Conversely, another clinical study examined the difficulty of the interhemispheric dissection for reaching upward-projecting ACoA aneurysms through the pterional approach. ${ }^{11}$ Downward-projecting ACoA aneurysms may adhere to the optic chiasm, and the frontal lobe retraction used in the pterional approach may cause premature bleeding and difficulty in controlling the contralateral $A_{1}$ segment. However, the subfrontal route through the mini-OZ approach provides a greater angle of attack to downward- or upward-projecting ACoA aneurysms, less frontal lobe retraction, and good exposure of the interhemispheric fissure and contralateral $\mathrm{A}_{1}$ segment 
TABLE 1. Aneurysm characteristics by location and approach type

\begin{tabular}{|c|c|c|c|c|}
\hline $\begin{array}{l}\text { Aneurysm Location } \\
\text { \& Approach }\end{array}$ & $\begin{array}{l}\text { No. of } \\
\text { Cases }^{*}\end{array}$ & Aneurysm Type & $\begin{array}{l}\text { No. of Ruptured } \\
\text { Aneurysms }\end{array}$ & $\begin{array}{c}\text { Aneurysm Size } \\
\text { (height or length) (mm)† }\end{array}$ \\
\hline \multicolumn{5}{|l|}{ MCA bifurcation $(n=176)$} \\
\hline Mini-OZ & 37 & 3 fusiform, 1 blister, 33 saccular & 6 & $6.1 \pm 4.2$ \\
\hline Mini-pterional & 109 & 12 fusiform, 97 saccular & 20 & $7.2 \pm 5.8$ \\
\hline \multicolumn{5}{|l|}{ ICA bifurcation $(n=77)$} \\
\hline Mini-OZ & 31 & 26 saccular, 5 blister & 7 & $6.42 \pm 3.35$ \\
\hline Mini-pterional & 27 & 23 saccular, 3 blister, 1 fusiform & 6 & $4.91 \pm 1.80$ \\
\hline \multicolumn{5}{|l|}{$\mathrm{ACo} A(n=65)$} \\
\hline Mini-OZ & 34 & 33 saccular, 1 blister & 21 & $5.30 \pm 2.60$ \\
\hline Mini-pterional & 8 & 8 saccular & 1 & $8.00 \pm 1.63$ \\
\hline \multicolumn{5}{|l|}{$\mathrm{PCoA}(\mathrm{n}=58)$} \\
\hline Mini-OZ & 18 & 17 saccular, 1 fusiform & 6 & $7.00 \pm 4.52$ \\
\hline Mini-pterional & 24 & 23 saccular, 1 fusiform & 6 & $8.42 \pm 6.01$ \\
\hline \multicolumn{5}{|l|}{ BA tip $(n=8)$} \\
\hline Mini-OZ & 3 & 2 blister, 1 saccular & 1 & $3.33 \pm 3.30$ \\
\hline Mini-pterional & 0 & & & \\
\hline \multicolumn{5}{|l|}{$\operatorname{PCA}(n=7)$} \\
\hline Mini-OZ & 1 & 1 fusiform & 1 & 3.2 \\
\hline Mini-pterional & 0 & & & \\
\hline \multicolumn{5}{|l|}{$\operatorname{SCA}(n=5)$} \\
\hline Mini-OZ & 3 & 3 saccular & 1 & $4.7 \pm 2.1$ \\
\hline Mini-pterional & 0 & & & \\
\hline
\end{tabular}

$\mathrm{ACOA}=$ anterior communicating artery; $\mathrm{BA}=$ basilar artery; $\mathrm{ICA}=$ internal carotid artery; $\mathrm{MCA}=$ middle cerebral artery; $\mathrm{OZ}=$ orbitozygomatic;

$\mathrm{PCOA}=$ posterior communicating artery; SCA = superior cerebellar artery.

* In the remaining cases for each location, the aneurysms were operated on using traditional approaches and thus are not reported here.

$\dagger$ Mean \pm SD. The size of saccular aneurysms is based on maximum height, and the size of fusiform aneurysms is based on maximum length.

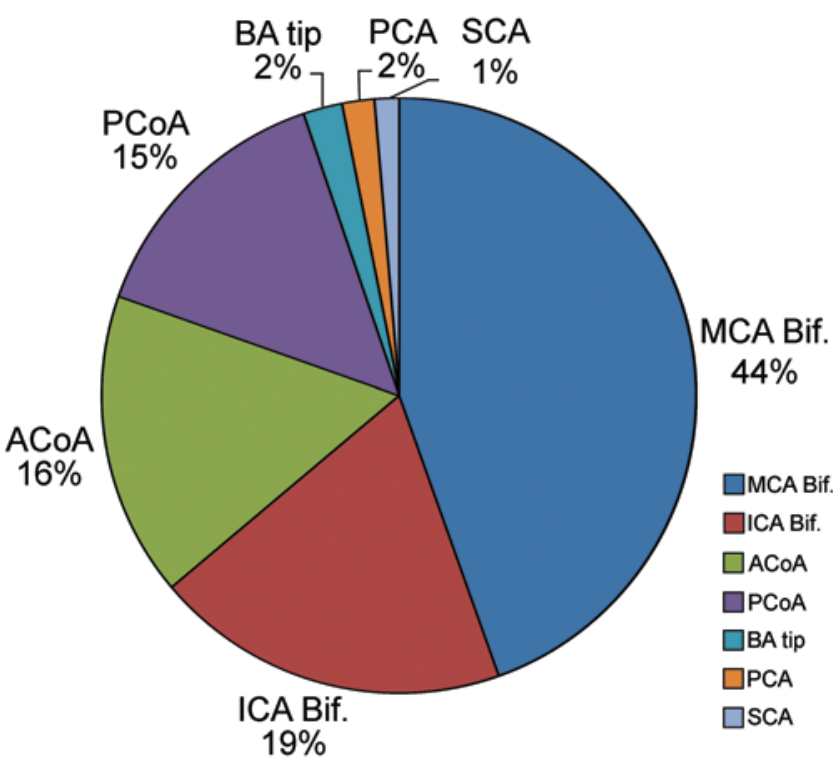

FIG. 10. Frequency of aneurysms by location operated on between January 2006 and November 2014. Percentages do not equal $100 \%$ because of rounding. Bif. = bifurcation. Figure is available in color online only.

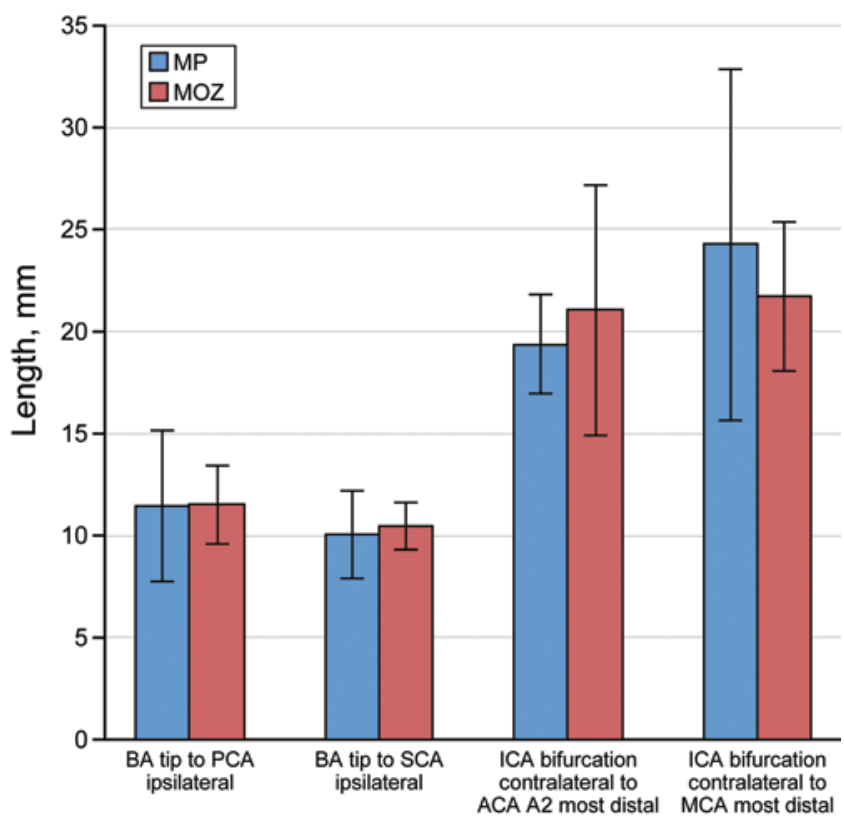

FIG. 11. Length of exposure of various anatomical features via the minipterional approach compared with the mini-OZ approach. Mean values are shown; error bars indicate standard deviations. Figure is available in color online only. 
of the ACA. Finally, the mini-pterional approach is a good choice for MCA bifurcation aneurysms, while the mini$\mathrm{OZ}$ approach is better for ACoA and ICA bifurcation, BA tip, and SCA aneurysms.

In another clinical study, Nathal and Gomez-Amador ${ }^{15}$ reviewed their results with the sphenoid ridge keyhole approach, which is similar to our current mini-pterional approach technique based on the incision, the splitting of the temporalis muscle, and the craniotomy. These investigators noted that this approach provides adequate access to the MCA bifurcation and most aneurysms arising from branches of the ICA. Their study supports our anatomical findings, such as surgical freedom and angle of attack of the mini-pterional approach (which they call the sphenoid ridge approach), and our clinical case selections. Mori et al. ${ }^{14}$ used the pterional keyhole approach, similar to the mini-pterional craniotomy, with a W-shaped periorbital skin incision and splitting of the temporalis muscle in patients with small $(<10 \mathrm{~mm}) \mathrm{MCA}$ aneurysms. Eighty-five percent of their patients had good cosmetic results (e.g., minimal skin scarring) postoperatively. Mori et al. did not report any permanent frontal muscle weakness postoperatively, although their incision was made in front of the hairline very close to the frontal (temporal) branches of the facial nerve. Although the incision in front of the hairline is directly over the craniotomy area, we do not use the facial incision to avoid poor cosmetic results because it risks damaging the branches of the facial nerve.

Sekhar et al. ${ }^{18}$ reported the addition of the posterolateral orbitotomy to the pterional craniotomy in a patient with subarachnoid hemorrhage caused by an ACoA aneurysm. When the subfrontal route is used to reach the ACoA aneurysm, removal of the posterolateral orbital wall provides less frontal lobe retraction and a more vertical (anteroposterior) angle of attack than that provided by a pterional craniotomy. We also remove the superior orbital rim, which provides a remarkable increase in the vertical angle of attack to the ACoA aneurysm with much less frontal lobe retraction. The mini-OZ approach is also superior to the lateral supraorbital approach described by Hernesniemi et al. ${ }^{10}$

\section{Conclusions}

The current mini-OZ and mini-pterional approaches provide less tissue traumatization (i.e., less temporal muscle manipulation, less brain parenchyma retraction) from the skin to the aneurysm in well-selected patients. In our experience, splitting or anterosuperior edge retraction techniques for the temporalis muscle result in less muscle atrophy postoperatively in both the mini-pterional approach and the mini-OZ approach. At our institution, the mini-OZ approach has been used preferentially for lesions of the ACoA and bifurcation of the ICA, while the mini-pterional approach has been used for aneurysms of the bifurcation of the MCA and the PCoA. Our anatomical quantitative analysis indicates that the mini-OZ approach provides better exposure to the contralateral side for controlling the contralateral parent arteries and multiple aneurysms. The minipterional approach offers more surgical freedom (maneuverability) for ipsilateral aneurysms of the circle of Willis.

\section{Acknowledgments}

The authors thank Kirsten Dorschel for data collection for this manuscript and the Neuroscience Publications staff at Barrow Neurological Institute for assistance with manuscript preparation. We thank the Newsome Family Endowment in Neurosurgery Research held by Dr. Preul, the Barrow Neurological Foundation, and Barrow Women's Foundation for providing funding for this study.

\section{References}

1. Caplan JM, Papadimitriou K, Yang W, Colby GP, Coon AL, Olivi A, et al: The minipterional craniotomy for anterior circulation aneurysms: initial experience with 72 patients. Neurosurgery 10 (Suppl 2):200-207, 2014

2. Chalouhi N, Jabbour P, Ibrahim I, Starke RM, Younes P, El Hage G, et al: Surgical treatment of ruptured anterior circulation aneurysms: comparison of pterional and supraorbital keyhole approaches. Neurosurgery 72:437-442, 2013

3. Cheng CM, Noguchi A, Dogan A, Anderson GJ, Hsu FP, McMenomey SO, et al: Quantitative verification of the keyhole concept: a comparison of area of exposure in the parasellar region via supraorbital keyhole, frontotemporal pterional, and supraorbital approaches. J Neurosurg 118:264-269, 2013

4. Czirják S, Nyáry I, Futó J, Szeifert GT: Bilateral supraorbital keyhole approach for multiple aneurysms via superciliary skin incisions. Surg Neurol 57:314-324, 2002

5. Figueiredo EG, Deshmukh P, Nakaji P, Crusius MU, Crawford N, Spetzler RF, et al: The minipterional craniotomy: technical description and anatomic assessment. Neurosurgery 61 (5 Suppl 2):256-265, 2007

6. Figueiredo EG, Deshmukh P, Nakaji P, Shu EB, Crawford N, Spetzler RF, et al: An anatomical analysis of the mini-modified orbitozygomatic and supra-orbital approaches. J Clin Neurosci 19:1545-1550, 2012

7. Figueiredo EG, Deshmukh P, Zabramski JM, Preul MC, Crawford NR, Spetzler RF: The pterional-transsylvian approach: an analytical study. Neurosurgery 62 (6 Suppl 3):1361-1367, 2008

8. Figueiredo EG, Teixeira MJ, Spetzler RF, Preul MC: Clinical and surgical experience with the minipterional craniotomy. Neurosurgery 75:E324-E325, 2014

9. Fischer G, Stadie A, Reisch R, Hopf NJ, Fries G, BöcherSchwarz H, et al: The keyhole concept in aneurysm surgery: results of the past 20 years. Neurosurgery 68 (1 Suppl Operative): $45-51,2011$

10. Hernesniemi J, Ishii K, Niemelä M, Smrcka M, Kivipelto L, Fujiki M, et al: Lateral supraorbital approach as an alternative to the classical pterional approach, in Yonekawa Y, Keller E, Sakurai Y, et al. (eds): New Trends of Surgery for Stroke and its Perioperative Management. Vienna: Springer, 2005, pp 17-21

11. Kashimura H, Kubo Y, Ogasawara K, Kakino S, Yoshida K, Ogawa A: Easy dissection of the interhemispheric fissure for treatment of the anterior communicating artery aneurysm by the pterional approach. World Neurosurg 73:688-690, 2010

12. Lan Q, Gong Z, Kang D, Zhang H, Qian Z, Chen J, et al: Microsurgical experience with keyhole operations on intracranial aneurysms. Surg Neurol 66 (Suppl 1):S2-S9, 2006

13. Lemole GM Jr, Henn JS, Zabramski JM, Spetzler RF: Modifications to the orbitozygomatic approach. Technical note. J Neurosurg 99:924-930, 2003

14. Mori K, Esaki T, Yamamoto T, Nakao Y: Individualized pterional keyhole clipping surgery based on a preoperative three-dimensional virtual osteotomy technique for unruptured middle cerebral artery aneurysm. Minim Invasive Neurosurg 54:207-213, 2011

15. Nathal E, Gomez-Amador JL: Anatomic and surgical basis of the sphenoid ridge keyhole approach for cerebral aneurysms. Neurosurgery 56 (1 Suppl):178-185, 2005 
16. Perneczky A, Reisch R: Keyhole Approaches in Neurosurgery. Volume 1: Concept and Surgical Technique. New York: Springer, 2008

17. Poblete T, Jiang X, Komune N, Matsushima K, Rhoton AL Jr: Preservation of the nerves to the frontalis muscle during pterional craniotomy. J Neurosurg 122:1274-1282, 2015

18. Sekhar LN, Natarajan SK, Britz GW, Ghodke B: Microsurgical management of anterior communicating artery aneurysms. Neurosurgery 61 (5 Suppl 2):273-292, 2007

\section{Disclosures}

The authors report no conflict of interest concerning the materials or methods used in this study or the findings specified in this paper.

\section{Author Contributions}

Conception and design: Preul, Yagmurlu, Safavi-Abbasi. Acquisition of data: Yagmurlu, Safavi-Abbasi. Analysis and interpretation of data: Yagmurlu, Belykh. Drafting the article: Preul, Yagmurlu. Critically revising the article: Preul, Yagmurlu. Reviewed submitted version of manuscript: Preul, Yagmurlu, Safavi-Abbasi, Kalani. Statistical analysis: Yagmurlu, Belykh. Study supervision: Preul, Nakaji, Rhoton, Spetzler.

\section{Correspondence}

Mark C. Preul, c/o Neuroscience Publications, Barrow Neurological Institute, St. Joseph's Hospital and Medical Center, 350 W. Thomas Rd., Phoenix, AZ 85013. email: neuropub@ dignityhealth.org. 